\title{
Radiological and CT findings in a extensive upper-limb involvement of Gorham's Disease: a case report Long $\operatorname{Xin}^{1 *}$, Zheng Tian ${ }^{2}$ and Shunwu Fan ${ }^{1}$
}

Addresses: ${ }^{1}$ Orthopaedic Laboratory, Clinic Medical Research Institution, Sir Run Run Shaw Hospital, Zhejiang University School of Medicine, NO.3 Qingchun Road, Hangzhou, 310016, Zhejiang Province, China and ${ }^{2}$ Department of Orthopaedics, The First Affiliated Hospital, Xinjiang Medical University, Xinjiang Province, 830002, China

Email: LX* - xinlonghz@yahoo.com.cn

* Corresponding author

Received: 18 November 2008 Accepted: 8 April 2009 Published: 10 June 2009

Cases Journal 2009, 2:7499 doi: 10.4076/1757-1626-2-7499

This article is available from: http://casesjournal.com/casesjournal/article/view/7499

(C) 2009 Xin et al; licensee Cases Network Ltd.

This is an Open Access article distributed under the terms of the Creative Commons Attribution License (http://creativecommons.org/licenses/by/3.0), which permits unrestricted use, distribution, and reproduction in any medium, provided the original work is properly cited.

\begin{abstract}
Introduction: The Gorham-Stout Syndrome (Gorham's massive osteolysis) is a rare condition in which spontaneous, progressive resorption of bone occurs. The etiology is poorly understood.

Case presentation: We reported here a patient who had begun insidiously and was characterized by extensive osteolysis in the left upper limb, with progressive carpal bone resorption. The characteristic radiological and CT findings were presented and the clinical presentation, diagnosis and surgical treatment were discussed in the case.

Conclusion: Gorham's disease is rarely involved in the whole upper limb. Histopathological evidences suggest that extensive osteolysis is caused by hemangiomatosis. The characteristic imaging findings may help us to differentiate from malignant neoplasm with progressive bony destruction.
\end{abstract}

\section{Introduction}

Gorham's syndrome is a rare disorder of unknown etiology characterized by a non-malignant proliferation of vascular structures originating in bone with progressive bony destruction and often extending into surrounding soft tissues $[1,2]$. Any part of the skeletal system can be affected. Complications depend on the site of bony involvement, ranging from mild discomfort to death. We presented a woman who revealed extensive osteolysis due to a progressive hemangiomatosis in the left upper limb.

\section{Case presentation}

A previously healthy 45-year-old woman was admitted with rapidly progressive pain in her left upper limb within one week, especially obvious swollen in the forearm. The pain was characterized as a dull ingravescence ache after onset despite conservative therapy. The deformity of left upper limb had strongly affected on her daily life. There was no history of trauma. Constitutional symptoms such as fever, anorexia, or weight loss were absent. Other skeletal examinations were normal. 


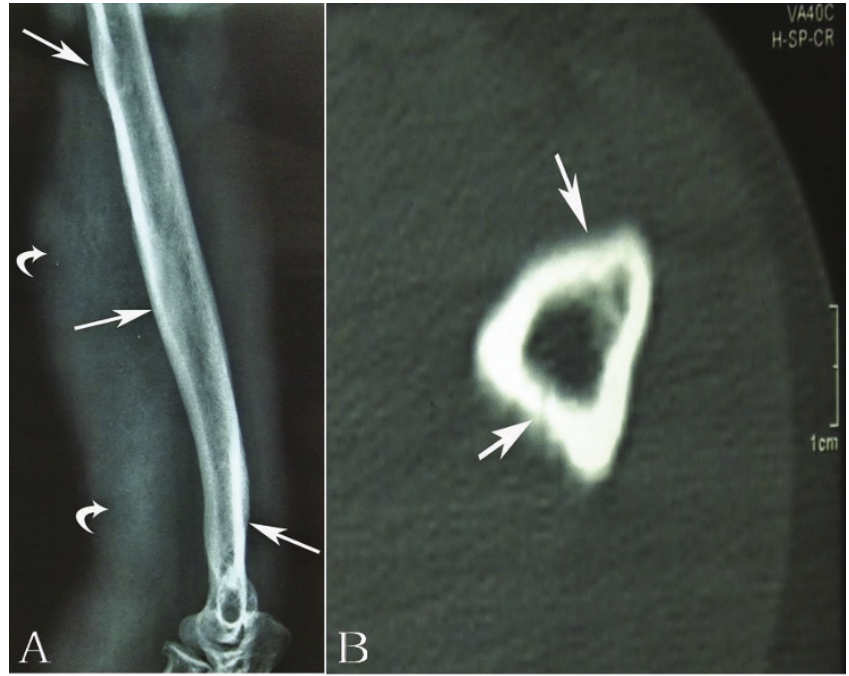

Figure I. (A) Radiograph of left humerus revealed extensive cortical thickening and prominent sclerosis (long arrow) were presented along the humeral shaft. Swellon soft-tissue mass (curved arrow) was also visible. (B) CT image demonstrated extensive periosteal reaction and cortical osteolysis were presented along the proximal humerus. The medial aspect of humerus showed irregular osteolysis with pathologic fractures. (white arrow).

On physical examination, multiple ill-defined swellings were palpated over the left upper limb. Some ecchymotic patches were distributed overlying the swelling. Range of motion of the left wrist was limited. No axillary lymph nodes were palpable. Laboratory investigations were normal apart from a mild elevation of the alkaline phosphatase.

Radiological examination revealed expansile cortical thickening and sclerosis were apparently presented along the humerus shaft (Figuer 1A). On computed tomography (CT), prominent periosteal reaction with intramedullary cortical destruction was correlated with the radiographic findings. Pathologic fractures were presented at the medial aspect of left humerus (Figure 1B). Radiograph of forearm showed expansive cortical thickening and aggressive periosteal reaction along aspect of the ulna and radius. Extensive osteolytic destructions were involved in the elbow joint. The lytic lesion of proximal radius was surrounded by a thin rim of sclerotic bone. The intramedullary and subcortical radiolucent foci resembled "patchy osteoporosis" (Figure 2A). Lamellar periosteal reaction was presented at the distal radius. The left carpal bone prominently showed multiple sharp margins of lytic lesions. The scaphoid, capitate and trapezium bones were involved. Soft tissue swellings over the abnormal bone were easily visible. (Figure 2B). CT image demonstrated

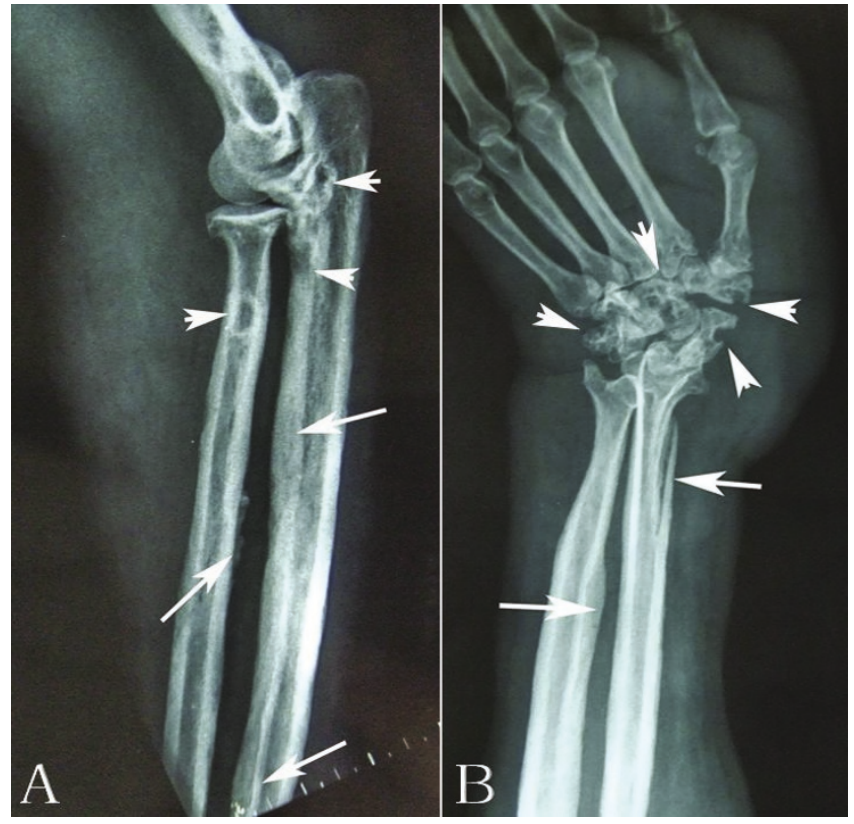

Figure 2. (A) Radiograph of forearm revealed extensive lytic defects (head arrow) along the proximal radius and ulna. Cortical thickening, sclerosis and aggressive periosteal reaction (long arrows) were presented in the proximal diaphyseal regions of both radius and ulna. (B) Multiple sharp margin of lytic lesions were scattered in the scaphoid, trapezium and capitate bone. (head arrows). Swollen soft tissue mass was also presented.

that aggressive periosteal reaction and multiple lytic lesions were presented at the proximal diaphysis of left ulna and radius. Cortical resorption and lytic destruction was obviously noted. (Figure 3A \& B). Because the lesion had an aggressive appearance on the plain radiographs and CT, a biopsy was performed to confirm the diagnosis. Histological examination of the specimen showed abundant intermediate-to-large ectatic vessels within a background of fibrous connective tissue intermixed with abnormal muscle fascicles. The marked proliferation of thin-walled capillaries was observed in the lesions (Figure 4A). The dilated vessels were embedded in connective tissue and small capillary-like vessels were dispersedly distributed in the stroma (Figure 4B). Pathologic examination revealed capillary hemangioma, and on the basis of the radiologic and clinical features, Gorham's disease was diagnosed. Massive resection and radiation therapy (total dose $3060 \mathrm{cGy}$ ) was planned. Two years after operation, there was no evidence of tumor recurrence.

\section{Discussion}

Gorham's disease is a very rare disorder characterized by bone loss (osteolysis) often associated with uncontrolled, destructive proliferation of vascular or lymphatic 


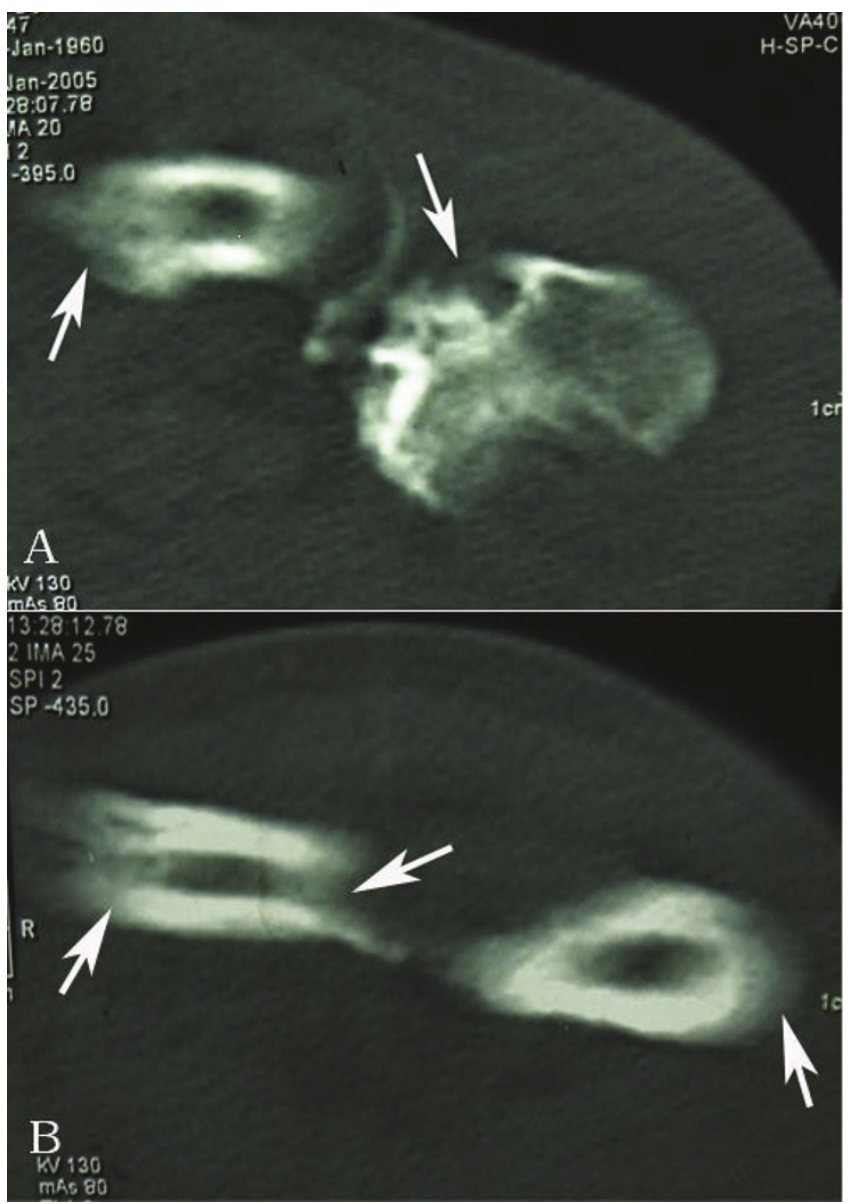

Figure 3. (A) CT image demonstrated aggressive periosteal reaction and multiple lytic lesions (long arrows) were presented at diaphysis of left ulna and radius. (B) Cortical resorption and lytic destruction (long arrows) was obviously noted.

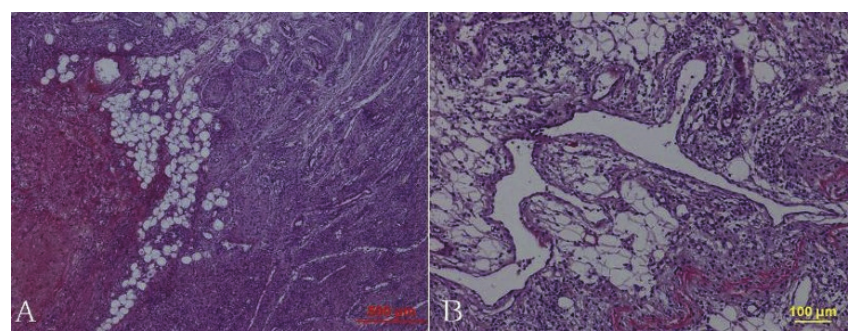

Figure 4. (A) Histologic photomicrograph (hematoxylin and eosin, $\times 40$ ) showed that variable-sized ectatic vessels were interlaced in the fibrous tissue and abnormal muscle fascicles. (B) The dilated vessels were embedded in connective tissue. (HE, × 100). capillaries within bone and surrounding soft tissue [1,3]. Most cases occur in children and young adults (usually less than 40 years of age) and no definite inheritance pattern has been reported. The natural history of Gorham's disease is unpredictable. It may spontaneously arrest or progress relentlessly until all osseous tissue disappears. Bone loss can occur in just one bone or spread to soft tissue and adjacent bones. In the case, our patient complained of dull aching pain and insidious onset of progressive weakness. The progressive bony destruction of left upper limb occurred over a period of eight months. Typical characteristics of acute spontaneous absorption of bone were noted.

Diagnosis of Gorham's disease is based on clinical and radiological features of loss of bones with histological evidence of angiomatous tumor. In most cases laboratory tests are usually within normal limits. The clinical presentation is variable, largely depending on the site of skeletal involvement. The characteristic radiographic and histopathological findings are helpful for making an early accurate diagnosis. The bones most commonly affected are the clavicle, scapula, humerus, ribs, and pelvis [4]. Radiographically, the destructive changes seen in the left upper limb mimicked malignant neoplasm due to aggressive osteolytic destruction with ill-defined lesion margins in this case. The resorption of left carpal bone was a distinguishing feature that could be differentiated from malignant neoplasm. CT scans showed extensive progressive osteolysis was involved in the whole left forearm. Soft tissue involvement was limited to the region around the bony abnormality. There does not appear to be a male or female predominance in patients with Gorham's disease. Most patients have been less than 40 years of age at the time of diagnosis [5]. The diagnosis should be made only after carefully excluding the complicated cause of osteolysis. Different forms of osteolysis such as, skeletal angiosarcoma, essential osteolysis and hereditary osteolysis must be ruled out by radiographic studies and appropriate blood tests [6]. A clinical suspicious case must be performed biopsy of the lesion.

The etiology of Gorham's disease is still speculative. There is substantial documentation that the disease has vascular or lymphatic proliferation with or without fibrosis $[2,7]$. Hemangiomatosis has been considered to be the characteristic feature related to the pathogenesis [1]. The progressive hemangiomatosis or lymphangiomatosis may extend to adjacent soft tissue or organs, such as the scapula, ribs or thoracic vertebra. A high morbidity and mortality is seen in patients with spinal or visceral involvement. The mechanism of bone resorption is unclear. There was no evidence of a malignant, neuropathic, or visceral component involved in our case. A biopsy confirmed extensive osteolysis was caused by progressive hemangiomatosis. 
Several therapeutic modalities include radiation therapy, anti-osteoclastic medications (bisphosphonates) and alpha-2b interferon have been used in the management of Gorham's disease [8-10]. No single treatment modality has proven effective in arresting the disease. Surgical treatment options include resection of the lesion and reconstruction using bone grafts or prostheses [11,12]. In recent years, most patients have been treated with surgery or radiation therapy. Massive resection and radiation therapy was treated in our patient. Two years after surgery, there was no evidence of tumor recurrence.

\section{Conclusion}

Gorham's disease is a very rare disorder characterized by bone loss. Our histopathological study provided good evidence that progressive osteolysis was always caused by significant vascular proliferation. Further studies are needed to elucidate the mechanisms underlying the progressive osteolysis that characterizes the disease.

\section{Consent}

Written informed consent was obtained from the patient for publication of this case report and accompanying images. A copy of the written consent is available for review by the Editor-in-Chief of this journal.

\section{Competing interests}

The authors declare that they have no competing interests.

\section{Authors' contributions}

All authors contributed the same.

\section{References}

I. Gorham LW, Stout AP: Massive osteolysis (acute spontaneous absorption of bone, phantom bone, disappearing bone); its relation to hemangiomatosis. J Bone Joint Surg Am 1955, 37-A: 985-1004.

2. Choma ND, Biscotti CV, Bauer TW, Mehta AC Licata AA: Gorham's syndrome: a case report and review of the literature. $A m$ J Med 1987, 83:1|5I-II56.

3. Gorham LW, Wright AW, Shultz HH, Maxon FC Jr: Disappearing bones: a rare form of massive osteolysis; report of two cases, one with autopsy findings. Am J Med 1954, 17:674-682.

4. Fisher KL, Pogrel MA: Gorham's syndrome (massive osteolysis): a case report. J Oral Maxillofac Surg 1990, 48: I222-1225.

5. Shives TC, Beabout JW, Unni KK: Massive osteolysis. Clin Orthop Relat Res 1993, 294:267-276.

6. Johnson PM, Mc CJ: Observations on massive osteolysis; a review of the literature and report of a case. Radiology 1958, 71:28-42.

7. Moller G, Priemel M, Amling M, Werner M, Kuhlmey AS, Delling G: The Gorham-Stout syndrome (Gorham's massive osteolysis). A report of six cases with histopathological findings. J Bone Joint Surg Br 1999, 81:501-506.

8. Fontanesi J: Radiation therapy in the treatment of Gorham disease. J Pediatr Hematol Oncol 2003, 25:816-8I7.

9. Hagberg H, Lamberg K, Astrom G: Alpha-2b interferon and oral clodronate for Gorham's disease. Lancet 1997, 350:1822-1823.

10. Hammer F, Kenn W, Wesselmann $U$ et al.: Gorham-Stout diseasestabilization during bisphosphonate treatment. J Bone Miner Res 2005, 20:350-353.
II. Turra S, Gigante C, Scapinelli R: A 20-year follow-up study of a case of surgically treated massive osteolysis. Clin Orthop Relat Res 1990, 250:297-302.

12. Poirier $\mathrm{H}$ : Massive osteolysis of the humerus treated by resection and prosthetic replacement. J Bone Joint Surg $\mathrm{Br}$ 1968, 50:158-160.

\section{Do you have a case to share?}

\section{Submit your case report today}

- Rapid peer review

- Fast publication

- PubMed indexing

- Inclusion in Cases Database

\section{Any patient, any case, can teach us something}

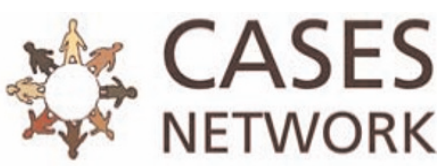

www.casesnetwork.com 